International Journal of Clinical Therapeutics and Diagnosis (1JCTD)

ISSN 2332-2926

\title{
Fueling Neuroscience with Human Pluripotent Stem Cells
}

$\mathrm{Lu} \mathrm{J}$

Editorial

Department of Neuroscience and Department of Neurology, School of Medicine and Public Health, Waisman Center, University of Wisconsin, Madison, WI 53705, USA.

\section{*Corresponding Author:}

Jianfeng Lu,

Waisman Center, University of Wisconsin, Madison, WI 53705, USA.

E-mail: jlu29@wisc.edu; healthygod_world@hotmail.com

Received: May 23, 2014

Published: June 11, 2014

Citation: Lu J (2014) Fueling Neuroscience with Human Pluripotent Stem Cells. Int J Clin Ther Diagn. 2(2e), 1-2. doi: http://dx.doi. org/10.19070/2332-2926-140003e

Copyright: $\mathbf{L u} \mathbf{J}^{\odot}$ 2014. This is an open-access article distributed under the terms of the Creative Commons Attribution License, which permits unrestricted use, distribution and reproduction in any medium, provided the original author and source are credited.

Since the discovery of the first embryonic stem cells (ESCs) from mice (Evans \& Kaufman, 1981; Martin, 1981), in vitro study on the mechanisms of neural development and neural degenerative disorders never stops (Berberi et al., 2003; Kawasaki et al., 2000;Lee et al., 2000; Lu \& Song, 2006; Lu et al., 2009;Pacherik et al., 2002; Strübing et al., 1995; Tropepe et al., 2001; Ying et al., 2003). With the isolation of the first human ESCs (Thomson et al., 1998), the dream of using these magic cells to understand the human being's brain and to treat the neural degenerative diseases starts showing in scientists' and clinicians' thoughts. In 2006 and 2007, Yamanaka group and Thomson group successfully generated mouse and human induced pluripotent stem cells (iPSCs) (Takahashi\&Yamanaka, 2006; Takahashi, et al., 2007; Yu et al., 2007), which not only overcomes the ethical issues brought by the isolation human ESCs, but also may in theory avoid immunosuppression reactions after autologous transplantation. This creation makes it possible to study the individualized human cells in vitro, especially the neural cells in the central nervous system (CNS), which usually are hard to obtain from live human beings. Human pluripotent stem cells (PSCs) derived neural cells have been globally used in the two major areas in neurosciences: 1 . Research on human neural system development and neural degenerative diseases' pathophysiologic process, which may help researchers find potential targets to treat diseases; 2. PSCs based pre-clinical/ clinical cell therapies(a part of personalized medical treatments).

\section{Understanding human neural development and neural diseases by PSCs}

Till now, most knowledge on the mammalians' neural system development is obtained from non-human being animals, such as rodents and monkeys. And because of the ethical issues, neural diseases were usually modeled in the text of non-human being animals, for example, modeling brain serotonin deficiency using rodents(summarized inLu, 2013a). Although non-human being animals share similar development pathways and may have similar pathophysiological processes during neural system diseases with human beings, as the very specific species in the world, human beings use unique and more complicated mechanisms to develop the most important control system--- neural system, and the pathophysiological processes during the development of disease may be more complex. Before the discovery of human PSCs, researchers had hard time to obtain human neural cells for in vitro culture and study; and it is even difficult to understand the development processes from embryonic cells to matured neurons or glial cells. Human PSCs, which can mimic the in vivo human being development in vitro, offer scientists a very powerful tool to study human neural development(Zhang et al., 2001).One of the typical examples is the in vitro specification of the spinal cord motor neurons with human ESCs (Li et al., 2005). Human ESCs as very early embryonic cells develop into embryonic bodies (EBs), which mimic the three germ layers stages; with the treatment of fibroblast growth factor 2 (FGF2), retinoic acid (RA) and sonic hedgehog $(\mathrm{SHH}), \mathrm{HB} 9+/ \mathrm{ChAT}+$ spinal motor neurons were generated from human ESCs. It is an interesting case to show how to use the knowledge from animals in the human in vitro development and how to use PSCs to demonstrate the unique properties of human being. Furthermore, human PSCs derived motor neurons make it possible to study the motor neuron related diseases, such as Amyotrophic lateral sclerosis (ALS) (Chen et al., 2014). Similar researches also happened on other neural diseases, such asDown syndrome (Weick et al., 2013) and Rett syndrome(Williams et al., 2014).

\section{Application of PSCs derived neural cells for treat- ing diseases}

Another important function of human PSCs derived neural cells is to treat neural system diseases. One typical example is the cell therapy trials for Parkinson's disease (PD). Human ESCs could be efficiently differentiated into midbrain dopaminergic neuron progenitors and then transplanted into PD animal's brain (Kirkeby et al., 2012; Kriks et al., 2011). As for the autologous transplantation, researchers are conducting related studies using non-primate animals, such as Rhesus monkey (Emborg et al., 2013).

It should be admitted that there is still a long way to go before the cell therapy could be applied in clinical environment. Scientists are trying their best to optimize the graft cells, either by generating PSCs without transgene integration(Hou et al., 2013; Lu, 2014; Obokata et al., 2014), or by directlyconverting human somatic cells into neural progenitors with non-integration virus (Lu, 2013b; Lu, 2013c; Lu et al., 2013). Reprogramming the in situ somatic cells in the brain may be another potential treatment for neural diseases (Guo et al., 2014; Lu et al., 2014). 


\section{References}

[1]. Barberi T, Klivenyi P, Calingasan N.Y (2003). Neural subtype specification of fertilization and nuclear transfer embryonic stem cells and application in parkinsonian mice. Nat Biotechnol 21:1200-1207.

[2]. Chen H, Qian K, Du Z (2014) Modeling ALS with iPSCs Reveals that Mutant SOD1 MisregulatesNeurofilament Balance in Motor Neurons. Cell Stem Cell. April 2nd, Epub ahead of print.

[3]. Chung S, Sonntag K.C, Andersson T (2002) Genetic engineering of mouse embryonic stem cells by Nurr1 enhances differentiation and maturation into dopaminergic neurons. Eur J Neurosci 16: 1829-1838.

[4]. Emborg M, Liu Y, Xi J (2013) Induced Pluripotent Stem Cell-Derived Neural Cells Survive and Mature in the Nonhuman Primate Brain. Cell Reports 3(3): 646-650

[5]. Evans M, Kaufman M (1981) Establishment in culture of pluripotent cells from mouse embryos. Nature 292 (5819): 154-156.

[6]. Guo Z, Zhang L, Wu Z (2014) In Vivo direct reprogramming of reactive glial cells into functional neurons after brain injury and in an Alzheimer's disease model. Cell Stem Cell 14(2):188-202.

[7]. Hou P, Li Y, Zhang X (2013) Pluripotent stem cells induced from mouse somatic cells by small-molecule compounds. Science 341(6146):651-654.

[8]. Kawasaki H, Mizuseki K, Nishikawa S (2000) Induction of midbrain dopaminergic neurons from ES cells by stromal cell derived inducing activity. Neuron 28: 31-40.

[9]. Kirkeby A, Grealish S, Wolf D.A (2012) Generation of regionally specified neural progenitors and functional neurons from human embryonic stem cells under defined conditions. Cell Rep 1:703-714.

[10]. Kriks S, Shim J.W, Piao J (2011) Dopamine neurons derived from human ES cells efficiently engraft in animal models of Parkinson's disease. Nature 480(7378):547-551.

[11]. Lee S.H, Lumelsky N, Studer L (2000) Efficient generation of midbrain and hindbrain neurons from mouse embryonic stem cells. Nat Biotechnol 18: 675-679

[12]. Li X .J, Du Z.W, Zarnowska E.D (2005). Specification of motoneurons from human embryonic stem cells. Nat Biotechnol. 23(2):215-221.

[13]. Lu J, Song H (2006) Progress in directed differentiation of mouse embryonic stem cells into neural cells. Journal of Chinese Medicine Research 6(5): 542-545.

[14]. Lu J, Tan L, Li P (2009) All-trans retinoic acid promotes neural lineage entry by pluripotent embryonic stem cells via multiple pathways. BMC Cell Biol 10:57.

[15]. Lu J (2013a) Transgenic Animal Models for Brain 5-HT Deficiency: An Editorial Summary. Journal of Genetic Syndromes \& Gene Therapy 4: e121.

[16]. Lu J (2013b) Progress in Clinical-Grade Induced Human Neural Stem Cells: An Editorial. JSM Genet Genomics 1:2.
[17]. Lu J (2013c) Reprogramming the Neurosciences. Journal of Genetic Syndromes \& Gene Therapy 5:124.

[18]. Lu J, Liu H, Huang C.T (2013) Generation of Integration-free and Region-Specific Neural Progenitors from Primate Fibroblasts. Cell Rep 3:1580-1591.

[19]. Lu J (2014) Reprogrammed Cells: How Far Away from the Clinical Use? Cloning \&Transgenesis 3:112.

[20]. Lu J, Bradley R, Zhang S. C (2014) Turning Reactive Glia into Functional Neurons in the Brain. Cell Stem Cell 14(2):133-134.

[21]. Martin G (1981) Isolation of a pluripotent cell line from early mouse embryos cultured in medium conditioned by teratocarcinoma stem cells. ProcNatlAcadSci USA 78 (12): 7634-7638.

[22]. Obokata H, Wakayama T, Sasai Y (2014) Stimulus-triggered fate conversion of somatic cells into pluripotency. Nature. 505(7485):641-647.

[23]. Pacherik K.J, Eslner M, Bryja V (2002) Neural differentiation of mouse embryonic stem cells grown in monolayer. ReprodNutr Dev 42: 317-326.

[24]. Strübing C, Ahnert-Hilger G, Shan J (1995) Differentiation of pluripotent embryonic stem cells into the neuronal lineage in vitro gives rise to mature inhibitory and excitatory neurons. Mech Dev 53: 275-287.

[25]. Takahashi K, Yamanaka S (2006) Induction of pluripotent stem cells from mouse embryonic and adult fibroblast cultures by defined factors. Cell 126: 663-676.

[26]. Takahashi K, Tanabe K, Ohnuki M (2007) Induction of pluripotent stem cells from adult human fibroblasts by defined factors. Cell131:861-872.

[27]. Thomson J, Itskovitz-Eldor J, Shapiro S (1998) Embryonic stem cell lines derived from human blastocysts. Science 282 (5391): 1145-1147.

[28]. Tropepe V, Hitoshi S, Sirard C (2001) Direct neural fate specification from embryonic stem cells: A primitive mammalian neural stem cell stage acquired through a default mechanism. Neuron 30: 65-78.

[29]. Weick J, Held D, Bonadurer G (2013) Deficits in human trisomy 21 iPSCs and neurons. Proceedings of the National Academy of Sciences of the United States of America May 28th. Online publication

[30]. Williams E, Zhong X, Mohamed A (2014) Mutant astrocytes differentiated from Rett syndrome patients-specific iPSCs have adverse effects on wild-type neurons. Human Molecular Genetics Jan.12th Online publication

[31]. Ying Q.L, Stavridis M, Griffiths D (2003) Conversion of embryonic stem cells into neuroectodermal precursors in adherent monoculture. Nat Biotechnol 21: 183-186.

[32]. Yu J, Hu K, Smuga-Otto K (2009) Human induced pluripotent stem cells free of vector and transgene sequences. Science 324(5928):797-801.

[33]. Zhang S.C, Wernig M, Duncan I.D (2001) In vitro differentiation of transplantable neural precursors from human embryonic stem cells. Nat Biotechnol 19(12):1129-1133. 